\title{
BMJ Open Rural family physician perspectives on communication with urban specialists: a qualitative study
}

\author{
Margo M Wilson (iD ,', Augustine Joshua Devasahayam, ${ }^{2}$ \\ Nathaniel J Pollock (D) , ${ }^{1,3,4}$ Adam Dubrowski, ${ }^{5}$ Tia Renouf ${ }^{1}$
}

To cite: Wilson MM, Devasahayam AJ, Pollock NJ, et al. Rural family physician perspectives on communication with urban specialists: a qualitative study. BMJ Open 2021;11:e043470. doi:10.1136/ bmjopen-2020-043470

- Prepublication history and additional online supplemental material for this paper are available online. To view these files, please visit the journal online (http://dx.doi.org/10. 1136/bmjopen-2020-043470)

Received 05 August 2020

Revised 20 December 2020

Accepted 18 February 2021
Check for updates

(C) Author(s) (or their employer(s)) 2021. Re-use permitted under CC BY-NC. No commercial re-use. See rights and permissions. Published by BMJ.

For numbered affiliations see end of article.

Correspondence to Dr Margo M Wilson; margo.wilson@med.mun.ca

\section{ABSTRACT}

Objective Communication is a key competency for medical education and comprehensive patient care. In rural environments, communication between rural family physicians and urban specialists is an essential pathway for clinical decision making. The aim of this study was to explore rural physicians' perspectives on communication with urban specialists during consultations and referrals. Setting Newfoundland and Labrador, Canada.

Participants This qualitative study involved semistructured, one-on-one interviews with rural family physicians $(n=11)$ with varied career stages, geographical regions, and community sizes.

Results Four themes specific to communication in rural practice were identified. The themes included: (1) understanding the contexts of rural care; (2) geographical isolation and patient transfer; and (3) respectful discourse; and (4) overcoming communication challenges in referrals and consultations.

Conclusions Communication between rural family physicians and urban specialists is a critical task in providing care for rural patients. Rural physicians see value in conveying unique aspects of rural clinical practice during communication with urban specialists, including context and the complexities of patient transfers.

\section{INTRODUCTION}

Communication is a key competency for medical education and practice, ${ }^{12}$ and a foundation of comprehensive patient care. The effectiveness of communication across practice settings and between healthcare providers also plays an important role in the quality and safety of care and on outcomes. In rural environments, clinical consultations and referrals between rural family physicians and urban specialists are essential pathways for sharing information and determining clinical management. Information exchange between rural and urban health systems provides a critical connection for patients transitioning between contexts that are often vastly different.

In Canada, universality and accessibility are core principles of healthcare. ${ }^{3}$ Yet, there are significant differences in access and outcomes

\section{Strengths and limitations of this study}

- Communication between rural family physicians and urban specialists is a cornerstone of comprehensive care for patients in rural communities.

- Understanding the resource constraints in rural health systems is necessary for making patientcentred decisions during consultations and referrals to specialty care.

- The logistics and complexities of patient transfers from rural to urban settings are key considerations during communication with urban specialists.

- Rural adaptations to standardised consultation processes and increased access and integration of telemedicine may help to enhance communication between rural and urban physicians.

- The sample did not include urban specialists or urban family physicians.

between rural and urban populations. ${ }^{4-6}$ People living in rural communities have higher rates of morbidity and mortality related to chronic disease and injuries compared with urban populations. ${ }^{56}$ Although Canada is an increasingly urbanised country, $28.3 \%$ of the population lives outside of a metropolitan area, and 6 million Canadians live in rural and remote areas. ${ }^{7}$ While patients often have access to primary care in rural communities, those who require specialised services that are not provided in their area need input from, and possibly transfer to, tertiary centres in cities, where the majority of specialised care is provided. ${ }^{8}$

Research on communication in healthcare has examined the dynamics and impact of communication on quality, safety and outcomes in clinical care. This includes studies about communication between different medical specialties, between physicians and allied health professions, and between physicians and patients. ${ }^{9} 10$ Communication problems that arise during transitions in patient care from physician to physician and changes in patient location are recognised as high-risk 
flashpoints for medical error and patient harm. ${ }^{11-17}$ Interventions that improve the effectiveness of communication between physicians, such as structured consultation models, have been shown to decrease adverse events and improve patient safety. ${ }^{18}$

The literature on healthcare communication has focused on urban, often tertiary care settings. ${ }^{919}$ There is comparatively limited evidence about communication experiences across diverse geographical contexts that are part of the same regional health system. Previous studies of rural and urban communication indicated physicians in both settings perceived barriers to effective communication. ${ }^{20}{ }^{21}$ Barriers included time constraints, power differentials, lack of trust, a lack of knowledge about rural contexts and a lack of information about patients. ${ }^{20}{ }^{21}$ Providing equitable and timely access to care for rural patients requires that systems overcome communication challenges.

The objectives of the present study were to examine rural family physician experiences with communication with urban specialists and to identify the dimensions of the consultation and referral process that are unique to rural practice. To do so, we sought to answer the following questions: (1) what are the communication experiences of rural family physicians during consultations and referrals to urban specialists? (2) what aspects of rural medicine impact the communication between rural family physicians and urban specialists? and (3) what changes could be made to the consultation and referral process that would improve communication and care for rural patients?

\section{METHODS}

We conducted a qualitative study with rural family physicians to understand their experiences related to clinical communication with urban specialists in tertiary care settings. The results of this study are reported in accordance with the Consolidated Criteria For Reporting Qualitative Research (online supplemental file 1). ${ }^{22}$

\section{Setting}

This study was conducted in the province of Newfoundland and Labrador, Canada. The province has a small population (521542 in 2019) distributed across two geographically separate areas with a combined landmass $\left(370514 \mathrm{~km}^{2}\right)$ that is larger than Ireland and the UK combined. The population density is low (1.4 people per $\mathrm{km}^{2}$ and aged (20\% aged 65 years or older). Healthcare is provincially funded and delivered through four regional health authorities. Tertiary care is available only in the capital city, St. John's, which is located in the eastern-most region of the province. In rural and remote areas, family physicians have a broad scope of practice that includes primary care, emergency medicine, low-risk obstetrics, palliative care, hospitalist care, and surgical assist. Select specialty services are provided in regional hospitals.
Medical travel by ground or air is common for patients in rural communities, especially those that require access to tertiary care and subspecialty services. Over $60 \%$ of the population in the province lives more than an hour by road from a tertiary care centre, and $40 \%$ reside more than 4 hours away. ${ }^{23}$ For patients from the most remote communities, especially those along the north coast of Labrador, travel to access an urban specialist can require two flights with a total distance of up to $1200 \mathrm{~km}$ by air. The trip often takes at least 8 hours of air travel time, and return flights cost at minimum $\$ \mathrm{C} 1800(\sim £ 1000)$ or more.

\section{Participants}

The sample frame for the study included all rural family physicians in Newfoundland and Labrador. A practice setting was considered rural if it was outside of the metro area of the capital city. Family physicians included all physicians who were licensed to practice family medicine by the medical licensure authority. In 2019, there were 629 licensed practising family physicians working in an estimated 431 full-time equivalent positions in the province $^{24} ; 56 \%$ of these physicians $(n=354)$ practised in a rural area and were potentially eligible to participate in the study.

We used a purposive sampling approach ${ }^{25}$ to include participants from varied career stages (early, mid, late), sex, and health regions. Potential participants were identified through team member professional networks related to clinical care and medical education. The principal investigator emailed $n=16$ eligible participants and invited them to take part in the study. Eleven rural family physicians agreed to participate and provided written informed consent. Participants were not remunerated. Recruitment ended after thematic saturation was reached.

The sample included participants from three out of the four health regions: Labrador-Grenfell $(n=6)$, Western $(n=1)$ and Eastern $(n=4)$. Participants were varied in their gender, years in practice, community and catchment area populations, and setting (table 1). Four participants were under a fee-for-service billing model; seven were salaried by the respective health authorities. All participants worked in communities that were accessible by road; seven participants also served boat-in/fly-in only communities in their region, some of which were Indigenous communities. Of the five individuals who declined, two did so due to scheduling conflicts, and three did not respond to invitations. Three of five individuals who declined were from the Eastern Health region.

\section{Data collection}

We conducted semistructured interviews with participants either in person at a location of their choice or via telephone between April 2018 and March 2019. In-person interviews occurred at hospitals and clinics, in homes, and at a conference. The interviews were conducted by one of two team members; respectively, they had postgraduate training and experience in rural family and 
Table 1 Participant characteristics

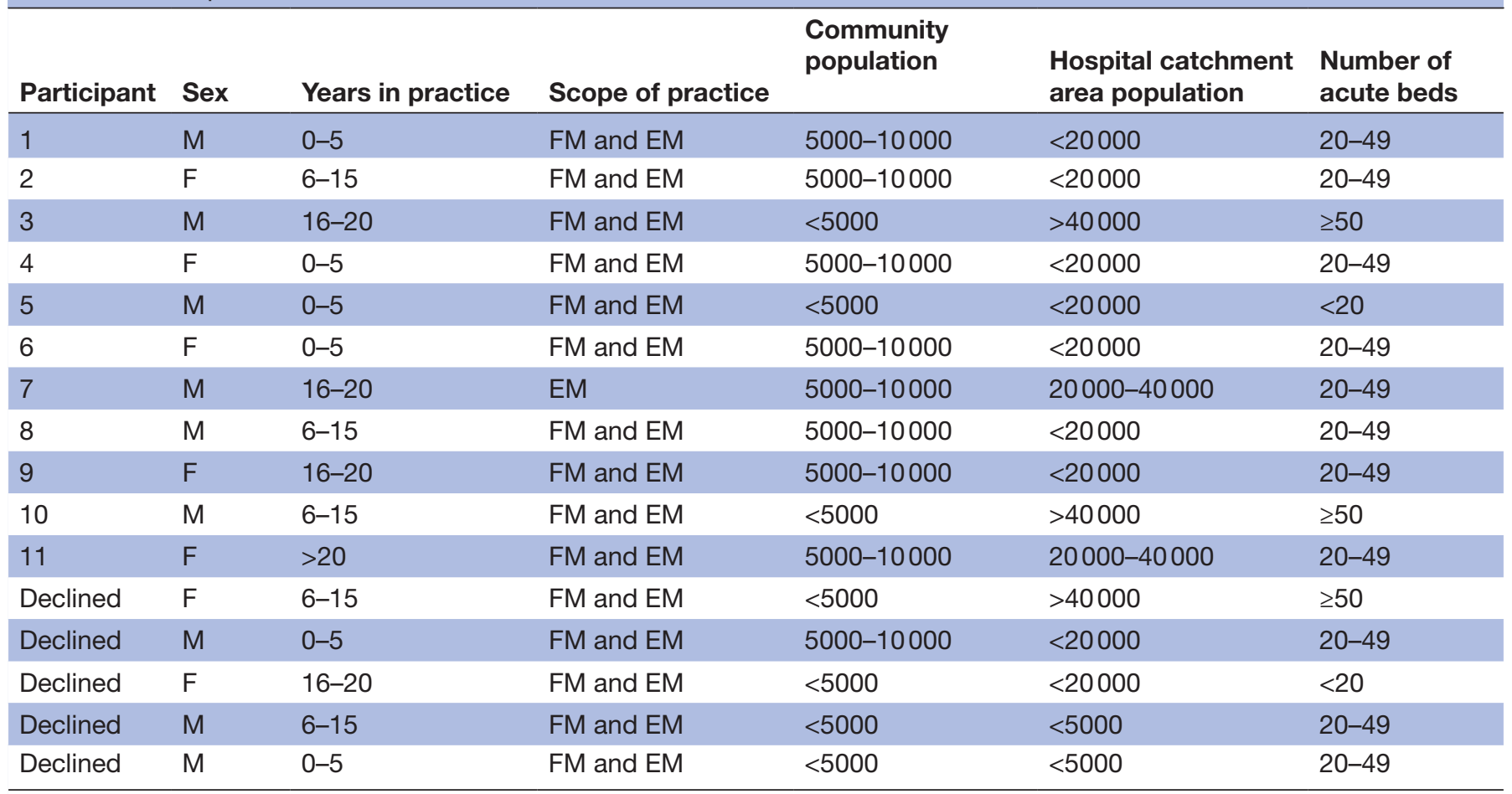

Range values were reported for Years in practice, Community population, Hospital catchment area population, and Number of acute care beds to decrease identifiability of setting and participant.

EM, emergency medicine; F, female; FM, family medicine; M, male.

emergency medicine (MMW), and graduate training in health services research and social work (NJP).

The interview questions (online supplemental file 2) were adapted based on findings from a previous study on communication between rural and urban physicians ${ }^{20}$ and factors that impact communication between primary care physicians and specialists. ${ }^{26}{ }^{27}$ The questions aimed to explore participant experiences related to clinical communication with urban specialists, identify features of the consultation and referral process that were unique to rural practice, and elicit strategies used by rural physicians to improve communication. All interviews were audio-recorded and transcribed verbatim by a professional transcriptionist. Interview duration ranged from 30 to $90 \mathrm{~min}$.

\section{Data analysis}

We used thematic analysis ${ }^{28}$ to examine the data. Coding involved both inductive and deductive techniques. ${ }^{29}$ The coding framework was informed by a previous study, ${ }^{20}$ and a conceptual framework for understanding rural health. ${ }^{30}$ New codes were generated through an iterative review of the recordings and transcripts. Two team members listened to the audio recordings immediately after the interviews, read the transcripts and wrote notes to become familiar with the data. ${ }^{28} 2911$ Two other team members reviewed a subsample of the transcripts prior to the development of a final coding framework. Themes were revised and refined through a comparison of interpretive memos and discussion about the relationships between categories. Discrepancies were inspected to ensure the validity of the analysis by consulting specific instances in the transcripts, discussing their relationship to themes and reaching consensus.

\section{Public and Patient involvement}

Members of the public and patients were not involved in the design or conduct of this study.

\section{Findings}

We identified four themes: (1) understanding the contexts of rural care; (2) geographic isolation and patient transfer; and (3) respectful discourse; and (4) overcoming challenges in consultations and referrals (figure 1).

\section{Understanding the contexts of rural care}

Participants emphasised the need to understand rural contexts as an integral part of communication between rural family physicians and urban consultants. They explained that dimensions of place in urban practices differ from those in rural and remote settings in terms of local resources and the availability of services, and the overlapping and interconnected nature of relationships.

Rural resource availability

Participants explained that there are varying levels of scarcity in rural health systems and that it is important to 


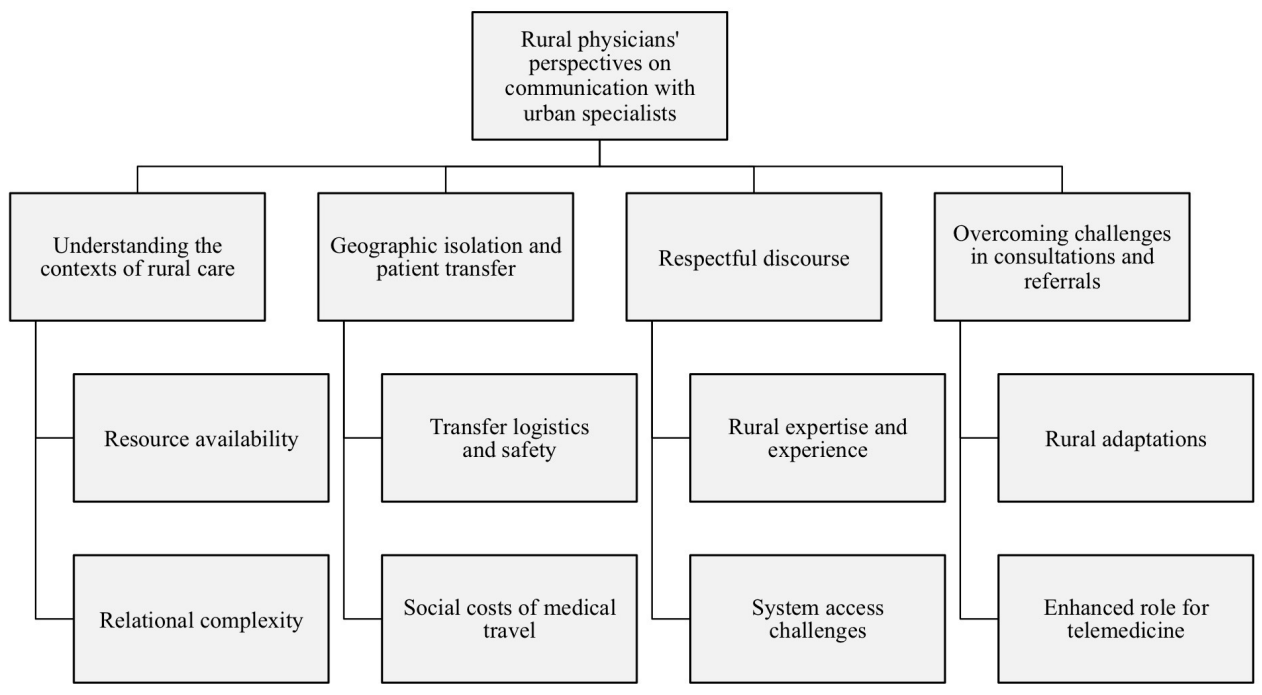

Figure 1 Rural family physician perspectives on communication.

describe these specific limitations during communication with urban consultants. The resources that exist in rural locations tend to be 'thinner' than those in cities. A participant explained that rural health systems need 'some way of better informing specialists about what resources we have and resources we don't have' in rural communities.

Participants indicated that being knowledgeable about rural contexts, such as the availability of specialised diagnostics and resource constraints, is critical for understanding the logistics and limits of patient care, especially in emergency scenarios (table 2).

Resource availability in rural settings can also shift over a short time in substantial ways, which in turn has consequences for patient care. Several participants noted that in their community's hospital, there is only one staff person available for diagnostic imaging. Calling in the laboratory technician several nights in a row for an emergency scan would disrupt the entire service in subsequent days (table 2).

Several participants reported that their hospitals have unpredictable gaps in internist and surgical specialty service, and there is no inherent system redundancy. The result is that the comprehensiveness of care is immediately decreased, and the gap in service access increases the need for patient transfers. Participants consistently indicated that these resource constraints are difficult to explain to urban colleagues over the phone.

\section{Relational complexity in rural contexts}

Participants explained that their clinical decisions are informed by knowledge about patients and the community that comes from experiences outside of healthcare settings. Rural physicians often have multiple roles in a community, beyond being a care provider. Through nonclinical roles, they gain insight into community history and culture, while also developing social relationships with patients and their families.

Participants shared that they often know a lot about a patient's social circumstances and family history because they have provided care to other family members, and interact outside of clinical settings. This adds complex dimensions to relationships between patients and providers in terms of social boundaries and professional ethics, but also provides unique insight into patient needs, which may be distinct from urban care. Participants shared that it is often challenging to convey to urban consultants how knowledge about patients from community settings comes to bear on clinical assessment and management (table 2). Rural physicians expressed that they incorporated not only the patient's wishes but also the patient's family experience into the consultation process.

\section{Geographical isolation and patient transfers}

The second theme relates to communication about patient transfers between rural sites and tertiary care centres. Participants indicated that the logistics and complexities of patient transfer are key considerations during consultations and referrals. Participants noted that the catchment

\section{Transfer logistics and safety}

The potential need for multiple transfers (community to regional rural hospital to urban tertiary care) adds a layer of complexity to each consultation (table 2). Participants noted that they consider factors such as the risk of patient's condition deteriorating during long wait and transfer times between sites, in addition to transfer logistics that are impacted by weather and infrastructure. Participants noted that transport risks and issues need to be part of the conversation during the decision making with consultants, but that these factors are not always readily understood. They also described the cognitive burden that patient transfers add to the consultation process. 
Table 2 Themes and illustrative quotes from participants

Theme Illustrative quote

Understanding the contexts of rural care

Rural resource 'I think it would give [consultants] a bit more appreciation when I say there's nothing we can do or when availability I say we can't keep an intubated patient [at our hospital] that we really can't and I'm not saying it to be difficult I'm just saying the reasons why it's not feasible.'

'There's only one (technician) in town, you know, and she's not on 24/7, and no one is paying her for that.'

Relational 'working in a rural center you know you can have honest conversations with people - you know their complexity family, you know where they live, and you can help them make decisions in their care that maximize the benefit to them without necessarily delving into extra testing'

'in the rural context where you tend to know people a bit more, you see them outside of the hospital and you can tell when things are right and when they're not.'

Geographical isolation and patient transfers

Transfer logistics 'Some (consultants) don't understand the environment that we're in here...so I've had experiences like and safety calling a cardiologist from a [remote] community and them saying like well why is that patient there and I'm saying well because they live here, and them saying well why can't you send them on a medevac to us tonight, and [me saying] because the runway doesn't have lights and we can't fly at night and just having this nonsense back and forth.'

'My answer back (to urban consultants) is do you think at 12:30-1:00 am on a stormy winter night that it is reasonable to put someone on the road...you have to decide well at what point in time is it worth the life and limb of our paramedics to transfer someone given the weather conditions?'

Social costs of 'If someone were to say 'Well, your choices for your mother are to be intubated and sent to St. John's medical travel at the ICU (intensive care unit) in the Health Sciences Centre, or you know we can keep your mom comfortable and she can stay (in her home community's hospital) knowing that we can't do x, y, or z.' I think patients are more comfortable knowing the extent of travel involved and the sort of disruption to the family life and social life and support networks.'

Respectful discourse

Rural expertise and 'I think they (consultants) appreciate that we do our very best with what we've got (in our community) and experience

that we really call them because we're stuck...they're very reassuring, and there's always that very open channel of communication.'

'the consultants that were the easiest to call and communicate with were the ones that had been in general practice before they went back to specialize.'

'(F)rom a family doctor side of things... we're the patient's advocate. So if we're calling (a specialist) it's for [the patient] and it's kind of our job to get the most out of this conversation as possible. So sometimes that means some moments of discomfort and feeling like you're asking too many questions or being too persistent. But this is so we can take good care of people and if you keep that in your mind you it can help you overcome some pretty uncomfortable phone calls.'

'[Some specialists] maybe perceive us (rural family physicians) to be no different than an urban nine-tofive office GP, without a great appreciation for again how much we are able to do with what little we have, and that when we say something is beyond us, that it really is.'

System access challenges
'You know we're all in this crappy system together, and I can't accept your patient sorry, but this is what you should do. We're in a crappy broken system that's too expensive.'

'I'll just let (consultants) vent...I've had (specialists) go on and on and on about their lives and all the things that they're doing and all the patients that they have and then they don't really ask me about all the patients that I have in my life, but I know that at the end of that venting I will eventually hear whether or not this patient is accepted in transfer and how I should manage them in the interim which is why I'm calling.'

Overcoming challenges in consultations and referrals

Rural adaptations 'My approach is to try to use a standardized way of opening the conversation with everybody and then just know that some people are going to be more antagonistic than others.'

'If you start the conversation by saying that you want advice, not that you're looking to transfer the patient, leaving it open ended, then [consultants] are very open and in that mindset, whereas I think if you don't say that upfront then they're kind of waiting for the ball to drop. You know? Just like, 'when are they are going to ask me to take this patient off their hands?"

Areas for their local clinics and hospitals serve smaller outlying communities, some of which are inaccessible by road. They noted that the long distance between communities, regional centres and tertiary care is a major obstacle, especially for emergency care. 
Social costs of medical travel

Participants explained that they also weigh the financial and social impacts of transport on patients and families when considering a transfer. Participants noted that travel costs for support persons or return travel for patients can be high and not always covered by government funding programmes. They also indicated that for the most remote communities, it could take 2 days or more of flying to return home from a tertiary care stay in the provincial capital. Decisions to transfer a patient may also be accompanied by less tangible risks that create a sense of dislocation and isolation from the community. The added time away from home can impact employment, family care, and access to social supports. Participants explained that urban specialists may not always be aware of the impact of transfer on patients. Participants recommended that for this reason, patients and families need to have an informed role in transfer decision making to help provide this perspective, where possible (table 2 ).

\section{Respectful discourse}

All participants talked about discursive features of their consultations with urban specialists. Participants indicated that their experiences interacting with urban colleagues were generally 'positive' and that the consultations conveyed a sense of 'mutual respect' between physicians. Participants identified two dimensions to mutual respect in consultations: (1) a respectful demeanour and (2) respect for clinical knowledge. They suggested that the presence of these qualities during consultations tended to differ across subspecialties. Colleagues who were described as having a 'lovely' and 'pleasant' demeanour with 'no condescending talk' were regarded by participants as being more helpful and engaged. By contrast, consultants who appeared 'difficult' in their demeanour tended to be described as needing to 'vent,' talk about their time constraints and being reluctant to accept referrals.

\section{Rural expertise and experience}

Rural family physicians explained that expressions of respect for their clinical expertise from urban colleagues helps to create a positive consultation experience and helps to facilitate open communication. Several participants noted that they requested consultations only when they were 'stuck.' The more 'positive' consultants were respectful of the clinical encounter that had taken place (table 2).

Participants consistently noted that, with experience, rural physicians improved their ability to have efficient and effective consultations. They attributed this to having more confidence in their care, learning to be more candid and clear about what they were asking for in consultations and referrals, and having built professional relationships with specialists over time. Participants noted that specialists who had done visiting clinics or locums in their rural community or who worked as family physicians were 'easier' to communicate with during consultations (table 2). Participants also commented on their role as advocates for patients, and that centring this purpose during their conversations can help with communication. Overall, participants explained that communication that demonstrated respect for rural physicians' scope of practice and clinical knowledge promoted collegiality and helped to foster a shared commitment to high-quality patient care.

\section{System access challenges}

One of the common sources of negative interactions in consultation processes was attributed to system accessibility issues (table 2). Participants reported that when the needs of either the referring or accepting physician could not be met, there was more likely to be conflict. This was often related to areas of access blockage in the system, such as pressure for beds. Participants emphasised the importance of seeking advice to promote collaboration, rather than immediately asking that patients be transferred. They also recognised that the increasing clinical demands of work contributed to an adversarial tone in the consultations.

\section{Overcoming challenges in consultations and referrals}

Although participants described several challenges related to their experiences communicating with urban consultants, rural family physicians also identified individual and system-level strategies to improve the quality, collegiality and efficiency of communication with urban colleagues.

\section{Rural adaptations}

At the individual level, many participants reflected on their process for consultation and made modifications. They described adapting consultation models from literature such as Situation, Background, Assessment, Recommendation $^{32}$ to fit rural practice by explaining possible transfer times and resource limitations. Several participants also talked about using a uniform structure in their consultation (table 2).

At the systems level, participants shared concerns that specialists are often not remunerated with medical billing fee codes for consultations, and that specialists may not have dedicated time to cover consultations from rural colleagues. Participants recommended that health systems establish mechanisms for protecting urban specialists' time to be involved in consultations with rural family physicians.

\section{Enhanced role for telemedicine}

One of the common changes proposed by participants was for the improved use of telemedicine. Participants noted that most consultations occur over the phone with no direct patient visuals. They indicated that rural physicians want increased access to communication technologies that can securely share access to photos and video from diagnostic testing and live patient encounters. There was consensus among participants that scaling up 'video conferencing abilities...where we're looking at 
(colleagues) eye to eye and we have a chance to have a consultant in front of a patient if we wanted to' would improve the effectiveness of consultations and collaborative decision making.

Several participants suggested that differentiating consultations according to urgency could help specialists prioritise and expedite a response to a consultation request. Participants noted that urgent consultations happen by phone, but non-urgent consultations are paper based and are often delayed in getting to the consultant. There was also a concern that telephone consultations are not recorded except via rural physicians' notes. Participants suggested that a robust platform that allows asynchronous and non-phone based consultation would help overcome gaps related to simple management questions, leaving phone calls for urgent consults.

\section{DISCUSSION}

Communication between rural family physicians and urban consultants is a critical dimension in rural patient care. This study identified challenges and facilitators unique to communication between rural family physicians and specialists in urban tertiary care. Specifically, we reported on themes related to the contexts of rural medicine, the complexity of geography and the need for respect for clinical knowledge.

\section{Rural health system resources}

Rural physicians identified that it was important to include and convey rural context issues in the consultation process. Health services and programmes in rural locales are often varied and dependent on local innovation and actors. ${ }^{30}$ Resource variability and scarcity are key elements in rural locations that directly impact patient care. Compared with urban locations, rural areas are more likely to adopt a primary health approach. ${ }^{33}$ While this approach is suited to rural settings, many patients still require specialised management.

When resource scarcity is an issue, rural practitioners often balance individual patient needs with the broader service requirements of their community. ${ }^{34}$ These unique layers of resource limitations are less likely present in urban hospitals. In rural environments, resource 'thinness' becomes an issue of health equity. Weighing these interests during a consultation process is important for rural physicians, but is not always understood by urban colleagues. This may explain why rural providers found it easier to communicate with consultants who had spent time in rural environments or general practice.

\section{Community relationships in rural medicine}

Health in a rural community is sociologically and culturally different from cities, as well as internally diverse. ${ }^{35}$ While urban practitioners can often maintain a separation between social and professional interactions, rural physicians must balance overlapping roles and social networks in their community. ${ }^{36}$ However, this relational complexity may also have an important role in clinical care because it provides rural physicians with place-based knowledge about patients, and an appreciation of clinical presentations situated in a particular family and community context. ${ }^{34}$ For example, rural clinicians consider not only clinical indications for patient transfers to urban tertiary care, which might also be mediated by context, but to also pay attention to factors such as the impact of leaving home and social supports on a patient's experience and outcomes.

Rural physicians in our study explained that this awareness can be difficult to convey to an urban specialist over the phone, particularly in an emergency situation. Similarly, participants found it hard to describe precisely how such knowledge influences clinical decision making, in part because it falls outside of standardised communication strategies. This sort of relational knowledge between rural physicians and patient families, and with communities, may be a way that power is shared in rural care. ${ }^{37}$

\section{Geography}

Geography is a major challenge for healthcare delivery in rural places and a key element in understanding of rural health. ${ }^{30}$ When a patient requires transport to a larger centre there are many factors that influence the transportation process. ${ }^{38}{ }^{39}$ Patient transport issues were a unique theme in the rural to urban consultation process. Rural physicians not only weighed the physiological risks of travel, but also the hidden costs of removing patients from their community of support, as well as a financial burden to the patient. Patients in rural communities often make trade-offs between accessing urban specialty services and incurring out-of-pocket expenses. ${ }^{40}{ }^{41}$ Rural physicians talk to their patients more about the economic burdens of care more than their urban counterparts. ${ }^{42}$ Participants explained that this consideration was often directly discussed in the consultation process and consistently influenced the thought process of rural physicians.

Previous work on consultation processes did not identify patient transport as an important issue, likely because consultation happened in one geographical location, such as transfer from the emergency department to the intensive care unit or from a clinic to a hospital from within the same city. ${ }^{43-45}$ The realities of transport influence not only the patients' and practitioners' decisions but are not formally recognised in any structured teaching about consultation. ${ }^{184546}$

\section{Power relations and the rural-urban divide}

Discourse features of the consultation process included structure, tone, and professionalism issues. Demonstrating respect for clinical skills was one of the main predictors of a successful consultation from the perspective of the rural physicians in our study. While mutual respect should be a baseline feature of communication, two hierarchies within medicine often interact to disrupt this goal. The first hierarchy elevates specialists over generalists, and has been identified as a key component of 
the hidden curriculum in medical schools. ${ }^{47}$ The second hierarchy is the rural-urban divide. One of the common frames when discussing rural health is a 'deficit' model. ${ }^{48}$ This underscores the limitations and lack of resources in a rural health system instead of highlighting the capacity for local care and innovation. ${ }^{36}$ Both of these hierarchical currents have the potential to sway the consultation discourse.

Participants in our study explained that the tone and professionalism of the consultation encounter were negatively influenced by systematic pressures such as bed availability and access to resources. Access is an ongoing problem in rural health. ${ }^{49}$ Both rural family physicians and urban specialists have multiple clinical responsibilities competing for their time, and telephone consultation is not included in billing fee codes in many jurisdictions. In previous studies, specialists have noted a reluctance to take on the increased workload and medico-legal risk for a process for which they are neither supported with reimbursement nor technology. ${ }^{44}$ In addition, there is often limited guidance for which service should take over patient care, especially in rural to urban connections. ${ }^{50}$ By not funding specialist support of rural colleagues, this support is inherently undervalued. As capacity stresses are universal, explicitly delineating duties of care can be a source of conflict during consultations.

\section{Rural-specific approaches to care}

Although there are substantial challenges for rural clinical care and health systems, rural-focused research needs to move beyond describing problems to identifying and testing solutions. ${ }^{48}$ In Canada, physician groups have highlighted the need to develop and apply rural-specific evidence and interventions. ${ }^{50} 51$

Technology and the appropriate use of telemedicine programmes have the potential to improve the consultation process. ${ }^{52}$ Physicians, educators and policy-makers should have an awareness of the geographical, economic and staffing capacity of rural environments prior to instituting any telemedicine programme. ${ }^{53}$ Rural physicians in our study viewed telemedicine as tool to enhance to the consultation process.

There is also a need for inter-professional communication skills in clinical training and continuing education. ${ }^{13}$ This study identifies several features of the consultation process that are unique to rural/urban communication. A future direction for research would be the development of a structured communication tool specific to the rural context.

\section{Limitations}

Our study had several limitations. The first was that the sample was drawn from a single provincial context. Some of the issues faced by rural physicians in Newfoundland and Labrador will likely be shared by physicians elsewhere, although specific features may vary across provincial and territorial health systems in Canada, and for rural contexts globally. While participants in this study described common challenges in communication, the focus was on the perspectives of those in rural practice. We did not include urban family physicians or specialists. It is possible that some of the aspects of communication with specialists are similar for family physicians in cities; perspectives from urban specialists may also provide added depth. Despite this limitation, this study is one of the few to examine the perspectives of rural physicians on communication with urban specialists.

A factor that may have impacted participant recruitment was that the lead (MMW) and senior (TR) authors were both practising urban physicians who had previous roles as rural practitioners in Newfoundland and Labrador and elsewhere. Since the community of physicians in the province is relatively small, both authors had pre-existing professional relationships with all participants. In one respect, this may have helped facilitate recruitment because research team members had already established trust with many of the potential participants through professional networks or collegial interactions; this may have made rural family physicians more likely to agree to take part in the study. Relatedly, these relationships may have also supported participants to be candid in their comments during the interviews. A possible unintended consequence of the relatively small medical community in the province is that rural physicians who were less familiar with research team members may have chosen not to participate. The absence of relationships between the research team members and physicians in one of the health regions (Central Health) may have contributed to the lack of success in recruitment from this area. Overall, this sort of relational complexity in the research process parallels the experiences described by participants in their clinical contexts. Rural physicians have multiple and overlapping roles in both geographically bound communities and in professional communities. This reality is especially pronounced in relatively small health systems.

\section{CONCLUSIONS}

The need to provide patient care in rural areas is a significant part of health service delivery in Canada. Communication between rural family physicians and urban specialists is vital for patient safety and care. This study examined the communication experiences of rural family physicians and identified features that were unique in the rural-to-urban consultation process. Conveying the rural context, understanding the challenges related to patient transfers, respecting rural expertise, and identifying opportunities for enhanced use of telehealth may all serve to improve the quality and effectiveness of communication between rural and urban settings.

\section{Author affiliations}

${ }^{1}$ Discipline of Emergency Medicine, Faculty of Medicine, Memorial University, St. John's, Newfoundland and Labrador, Canada

${ }^{2}$ Toronto Rehabilitation Institute, University of Toronto, Toronto, Ontario, Canada

${ }^{3}$ School of Arctic and Subarctic Studies, Labrador Institute, Memorial University, Happy Valley-Goose Bay, Newfoundland and Labrador, Canada

${ }^{4}$ Division of Community Health and Humanities, Faculty of Medicine, Memorial University, St. John's, Newfoundland and Labrador, Canada 
${ }^{5}$ Faculty of Health Sciences, University of Ontario Institute of Technology, Oshawa, Ontario, Canada

\section{Twitter Margo M Wilson @margomwilson and Nathaniel J Pollock @njpollock}

Acknowledgements Thank you to the administrative and support staff in the Discipline of Emergency Medicine and the Faculty of Medicine at Memorial University including Joanne Doyle, Melanie Doyle, Dr. Charlene Simmonds and staff at the Health Research Unit, Nicole Bishop, and Dr. Meghan Morrison for providing assistance with this project. Thank you to Dr. Elise Thorburn for reviewing and providing feedback on this manuscript. Thank you to Dr. Shabnam Asghari, Dr. Ali Modir-Rousta, and Jonathan Price at the Centre for Rural Health Studies for funding and administrative support through the Rural 360 grant and the 6for6 program.

Contributors MMW, TR, AD, AJD, and NJP designed the study; TR and AD obtained research ethics approval; MMW and NJP collected and transcribed the data; MWW TR, NJP and AJD analysed the data; all authors interpreted the results, drafted and revised the manuscript, and read and approved the final version.

Competing interests None declared.

Patient consent for publication Not required.

Ethics approval The study was received ethics approval from Memorial University's Interdisciplinary Committee on Ethics in Human Research (\#20180082).

Provenance and peer review Not commissioned; externally peer reviewed.

Data availability statement No data are available as the authors do not have consent from participants to share record-level data.

Supplemental material This content has been supplied by the author(s). It has not been vetted by BMJ Publishing Group Limited (BMJ) and may not have been peer-reviewed. Any opinions or recommendations discussed are solely those of the author(s) and are not endorsed by BMJ. BMJ disclaims all liability and responsibility arising from any reliance placed on the content. Where the content includes any translated material, BMJ does not warrant the accuracy and reliability of the translations (including but not limited to local regulations, clinical guidelines, terminology, drug names and drug dosages), and is not responsible for any error and/or omissions arising from translation and adaptation or otherwise.

Open access This is an open access article distributed in accordance with the Creative Commons Attribution Non Commercial (CC BY-NC 4.0) license, which permits others to distribute, remix, adapt, build upon this work non-commercially, and license their derivative works on different terms, provided the original work is properly cited, appropriate credit is given, any changes made indicated, and the use is non-commercial. See: http://creativecommons.org/licenses/by-nc/4.0/.

\section{ORCID iDs}

Margo M Wilson http://orcid.org/0000-0002-2450-8285

Nathaniel J Pollock http://orcid.org/0000-0001-5699-7661

\section{REFERENCES}

1 Frank JR, Danoff D. The CanMEDS initiative: implementing an outcomes-based framework of physician competencies. Med Teach 2007;29:642-7.

2 Laughlin T, Wetmore S, Allen T, et al. Defining competency-based evaluation objectives in family medicine: communication skills. Can Fam Physician 2012;58:e217-24.

3 Minister of Justice. Canada health act (R. S.C., 1985, C. C-6). Government of Canada, 2017: 1-18.

4 Shah TI, Clark AF, Seabrook JA, et al. Geographic accessibility to primary care providers: comparing rural and urban areas in southwestern Ontario. Canadian Geographer/Le Géographe canadien 2020;64:65-78.

5 Pong RW, DesMeules M, Heng D, et al. Patterns of health services utilization in rural Canada. Chronic Dis Inj Can 2011;31:1-36.

6 Pong RW, DesMeules M, Lagacé C. Rural-urban disparities in health: how does Canada fare and how does Canada compare with Australia? Aust J Rural Health 2009;17:58-64.

7 Statistics Canada. Table 17-10-0135-01: population estimates, July 1 , by census metropolitan area and census agglomeration, 2016 boundaries, 2020.

8 Agency for Healthcare Research Quality. National healthcare quality and disparities report Chartbook on rural health care, 2017.

9 Liu JJ, Rotteau L, Bell CM, et al. Putting out fires: a qualitative study exploring the use of patient complaints to drive improvement at three academic hospitals. BMJ Qual Saf 2019;28:894-900.
10 Hernan AL, Giles SJ, Fuller J, et al. Patient and carer identified factors which contribute to safety incidents in primary care: a qualitative study. BMJ Qual Saf 2015;24:583-93.

11 Greenberg CC, Regenbogen SE, Studdert DM, et al. Patterns of communication breakdowns resulting in injury to surgical patients. J Am Coll Surg 2007;204:533-40.

12 Leonard M, Graham S, Bonacum D. The human factor: the critical importance of effective teamwork and communication in providing safe care. Qual Saf Health Care 2004;13:i85-90.

13 Manias E, Geddes F, Watson B, et al. Perspectives of clinical handover processes: a multi-site survey across different health professionals. J Clin Nurs 2016;25:80-91.

14 Vincent C, Taylor-Adams S, Stanhope N. Framework for analysing risk and safety in clinical medicine. BMJ 1998;316:1154-7.

15 Petersen LA, Brennan TA, O'Neil AC, et al. Does housestaff discontinuity of care increase the risk for preventable adverse events? Ann Intern Med 1994;121:866-72.

16 Moore C, Wisnivesky J, Williams S, et al. Medical errors related to discontinuity of care from an inpatient to an outpatient setting. $J$ Gen Intern Med 2003;18:646-51.

17 Kripalani S, LeFevre F, Phillips CO, et al. Deficits in communication and information transfer between hospital-based and primary care physicians: implications for patient safety and continuity of care. JAMA 2007;297:831-41.

18 Kessler CS, Afshar Y, Sardar G, et al. A prospective, randomized, controlled study demonstrating a novel, effective model of transfer of care between physicians: the 5 Cs of consultation. Acad Emerg Med 2012;19:968-74.

19 Arora V, Johnson J, Lovinger D, et al. Communication failures in patient sign-out and suggestions for improvement: a critical incident analysis. Qual Saf Health Care 2005;14:401-7.

20 Renouf T, Alani S, Whalen D, et al. City mouse, country mouse: a mixed-methods evaluation of perceived communication barriers between rural family physicians and urban consultants in Newfoundland and Labrador, Canada. BMJ Open 2016;6:e010153.

21 Grant IN, Dixon AS. "Thank you for seeing this patient": studying the quality of communication between physicians. Can Fam Physician 1987;33:605

22 Tong A, Sainsbury P, Craig J. Consolidated criteria for reporting qualitative research (COREQ): a 32-item checklist for interviews and focus groups. Int J Qual Health Care 2007;19:349-57.

23 Hameed SM, Schuurman N, Razek T, et al. Access to trauma systems in Canada. J Trauma 2010;69:1350-61.

24 Thompson R. Physician resource forecast for family medicine newfoundland and labrador, 2019.

25 Patton MQ. Qualitative research \& evaluation methods: Integrating theory and practice. Sage publications, 2014.

26 O'Malley AS, Reschovsky JD. Referral and consultation communication between primary care and specialist physicians: finding common ground. Arch Intern Med 2011;171:56-65.

27 Zuchowski JL, Rose DE, Hamilton AB, et al. Challenges in referral communication between VHA primary care and specialty care. J Gen Intern Med 2015;30:305-11.

28 Braun V, Clarke V. Using thematic analysis in psychology. Qual Res Psychol 2006;3:77-101.

29 Green J, Thorogood N. Qualitative methods for health research. Sage Publications Limited, 2004.

30 Bourke L, Humphreys JS, Wakerman J, et al. Understanding rural and remote health: a framework for analysis in Australia. Health Place 2012;18:496-503.

31 Birks M, Chapman Y, Francis K. Memoing in qualitative research: probing data and processes. J Res Nurs 2008;13:68-75.

32 Haig KM, Sutton S, Whittington J. SBAR: a shared mental model for improving communication between clinicians. Jt Comm J Qual Patient Saf 2006;32:167-75.

33 Hartley D. Population health, and rural culture. Am J Public Health 2004:94:1675-8.

34 Konkin J, Grave L, Cockburn E, et al. Exploration of rural physicians' lived experience of practising outside their usual scope of practice to provide access to essential medical care (clinical courage): an international phenomenological study. BMJ Open 2020;10:e037705.

35 Wakerman J, Humphreys JS. Rural health: why it matters. Med J Aust 2002;176:457-8.

36 Simpson C, McDonald F. Rethinking rural health ethics. Rethinking Rural Health Ethics: Springer, 2017: 161-71.

37 Nimmon L, Stenfors-Hayes T. The "Handling" of power in the physician-patient encounter: perceptions from experienced physicians. BMC Med Educ 2016;16:114.

38 Young TK, Tabish T, Young SK, et al. Patient transportation in Canada's Northern territories: patterns, costs and providers perspectives. Rural Remote Health 2019;19:5113-13. 
39 Nolan B, Haas B, Tien $\mathrm{H}$, et al. Causes of delay during interfacility transports of injured patients transported by air ambulance. Prehosp Emerg Care 2020;24:625-33.

40 Wong ST, Regan S. Patient perspectives on primary health care in rural communities: effects of geography on access, continuity and efficiency. Rural Remote Health 2009;9:1142.

41 Mathews M, West R, Buehler S. How important are out-of-pocket costs to rural patients' cancer care decisions? Can J Rural Med 2009;14:54-60.

42 Kirchhoff AC, Hart G, Campbell EG. Rural and urban primary care physician professional beliefs and quality improvement behaviors. $J$ Rural Health 2014;30:235-43.

43 Dunsford J. Structured communication: improving patient safety with SBAR. Nurs Womens Health 2009;13:384-90.

44 Wadhwa A, Lingard L. A qualitative study examining tensions in interdoctor telephone consultations. Med Educ 2006;40:759-67.

45 Chan T, Orlich D, Kulasegaram K, et al. Understanding communication between emergency and consulting physicians: a qualitative study that describes and defines the essential elements of the emergency department consultation-referral process for the junior learner. CJEM 2013;15:42-51.
46 Kessler CS, Chan T, Loeb JM, et al. I'm clear, you're clear, we're all clear: improving consultation communication skills in undergraduate medical education. Acad Med 2013;88:753-8.

47 Mahood SC. Medical education: beware the hidden curriculum. Can Fam Physician 2011;57:983-5.

48 Bourke L, Humphreys JS, Wakerman J, et al. From 'problemdescribing' to 'problem-solving': Challenging the 'deficit' view of remote and rural health. Aust J Rural Health 2010;18:205-9.

49 Bourke L, Sheridan C. Understanding rural health-key concepts. In: A textbook of Australian rural health. Canberra: Australian Rural Health Network, 2008: 31-43.

50 Wilson CR, Rourke J, Oandasan IF, et al. Progress made on access to rural healthcare in Canada. Can J Rural Med 2020;25:14.

51 Patey C, Asghari S, Norman P, et al. Redesign of a rural emergency department to prepare for the COVID-19 pandemic. CMAJ 2020;192:E518-20.

52 Smith AC, Bensink M, Armfield N, et al. Telemedicine and rural health care applications. J Postgrad Med 2005;51:286.

53 Sims CA, Holena D, Kim P, et al. Effect of low-dose supplementation of arginine vasopressin on need for blood product transfusions in patients with trauma and hemorrhagic shock: a randomized clinical trial. JAMA Surg 2019;154:994. 